\section{Descubrimiento sorprendente sobre los vectores resistentes a los plaguicidas}

El rociamiento con plaguicidas hasta ahora ha constituido el medio principal para combatir las enfermedades transmitidas por mosquitos, como la malaria y la filariasis. Pero un descubrimiento sorprendente pone en duda la idoneidad de este enfoque. Según un estudio reciente efectuado en el Asia, los mosquitos Culex quinquefasciatus resistentes a los insecticidas son menos propensos a transmitir la filariasis tropical que los que son susceptibles. Si este asombroso hallazgo se aplica por igual a otras especies de insectos transmisores de enfermedades, las consecuencias para el control de las enfermedades transmitidas por vectores podrían ser gigantescas. Por años, la premisa clásica de que un menor número de mosquitos resistentes se traduce en una menor tasa de transmisión ha llevado a los investigadores a dedicar un grande y prolongado esfuerzo a descubrir nuevos plaguicidas contra los cuales no haya resistencia. Pero de ser válidos los resultados de este estudio reciente, todo este empeño podría haber sido inútil y hasta contraproducente en lo que respecta a la lucha contra las enfermedades transmitidas por vectores.

Una de las esterasas que se encuentran en los mosquitos resistentes se expresa con mayor intensidad en el aparato digestivo del insecto y en sus glándulas salivales, capa subcuticular y túbulos de Malpighi, lo cual altera el potencial de reducción y oxidación de las células que integran estas estructuras. Ya que las larvas de los parásitos tienen que atravesar estos tejidos para alcanzar su pleno desarrollo, es posible que la supervivencia del parásito $y$, por ende, la capacidad del insecto para funcionar como vector, se vea directamente afectada por la resistencia del insecto a los plaguicidas. Ello podría explicar por qué suele haber menos parásitos en los mosquitos resistentes.

Mecanismos de resistencia de este tipo se han detectado en Anopheles albimanus y A. culicifacies, mosquitos transmisores de la malaria. La investigación que ha arrojado los resultados sorprendentes fue dirigida por Janet Hemingway de la Universidad de Cardiff, Reino Unido, en mosquitos Culex quinquefasciatus hallados en viviendas de pacientes con filariasis en Sri Lanka. De ella se desprende el siguiente interrogante: $¿$ Se debe fomentar activamente la supervivencia de mosquitos resistentes a los plaguicidas? Según Hemingway, sería erróneo concluir que sí, en vista de que la proliferación descontrolada de la población de mosquitos resistentes redundaría a la larga en un aumento general de la transmisión. (McCarroll L, Paton MG, Karunaratne SHPP, Jayasuryia HTR, Kalpage KSP, Hemingway J. Insecticides and mosquito-borne disease. Nature 2000;407:961-962.)

\section{El antígeno 3 de la fase intrahepática: ¿base para una vacuna contra la malaria?}

Aunque los mecanismos no se han dilucidado, se sabe que en seres humanos se consigue inmunidad contra la malaria mediante la exposición a miles de picaduras de anofelinos infestados que han sido sometidos a irradiación. Partiendo de esta observación, se han elaborado vacunas a base de esporozoitos irradiados. Sin embargo, la capacidad inmunógena de estas vacunas es pobre y existe el inconveniente de que los esporozoitos son muy difíciles de cultivar en el laboratorio. Por lo tanto, la única forma de administrarlos que da buenos resultados consiste en exponer al individuo a centenares de picaduras de mosquitos infectados en 12 a 14 ocasiones distintas.

Las vacunas elaboradas hasta ahora a partir de subunidades parasitarias no confieren un grado similar de protección. No obstante, estudios recientes indican que los parásitos de fase intrahepática o preeritrocítica, que es la posterior a la picadura, desempeñan una función esencial en la producción de inmunidad debido a la presencia en ellos del antígeno 3 (LSA-3), proteína con un peso de 200 kilodaltones, que posee propiedades inmunógenas y antigénicas notables.

Un grupo de investigadores europeos identificó el gen completo del LSA-3 y determinó su secuencia de bases, expresión, ubicación y grado de conservación. Usó como modelo al chimpancé (Pan troglodytes), cuya tasa de transformación de esporozoitos en trofozoitos intrahepáticos es muy similar a la del ser humano, para poner a prueba una "vacuna" a base de lipopéptidos y proteínas recombinantes del LSA-3. La inmunización con LSA-3 confirió protección contra provocaciones heterólogas posteriores con esporozoitos de P. falciparum administrados en grandes cantidades. Los buenos resultados obtenidos confirmaron que el antígeno LSA-3 
de P. falciparum intrahepático es un buen candidato para la elaboración de una vacuna contra la malaria. (Daubersies $\mathrm{P}$, Thomas AW, Millet $\mathrm{P}$, Brahimi $\mathrm{K}$, Langermans JAM, Ollomo B, et al. Protection against Plasmodium falciparum malaria in chimpanzees by immunization with the conserved preerythrocytic liver-stage antigen 3. Nature Med 2000; 6(11):1258-1263.)

\section{¿Cuánto tiempo hay que fumar para volverse adicto al cigarrillo?}

Siempre se ha pensado que la dependencia de la nicotina, que se caracteriza por tolerancia, ansia de fumar y síntomas de abstinencia cuando no se fuma, se produce poco a poco y después de un largo consumo cotidiano de cigarrillos de un mínimo de media cajetilla. Esta creencia se ha basado en el hecho de que algunos adultos, cuyos niveles de absorción y metabolismo de la nicotina no difieren de los de otros fumadores, no desarrollan dependencia pese a que fuman hasta un máximo de cinco cigarrillos diarios. Pero es hora de reexaminar esta creencia, según indican los resultados de un estudio efectuado en adolescentes en el que se examinó la relación entre la aparición de los primeros síntomas de dependencia y la duración y frecuencia del consumo de tabaco.

Los adolescentes estudiados formaron parte de una cohorte de 681 estudiantes de séptimo grado entre las edades de 12 y 13 años. El período de seguimiento fue de un año y la información sobre el consumo de tabaco se obtuvo mediante tres entrevistas confidenciales con cada estudiante durante ese período. El período de latencia hasta la aparición de síntomas de dependencia se calculó a partir del momento en que el estudiante empezaba a fumar con una frecuencia mínima de una vez al mes.

Se encontró que $22 \%$ de los 95 sujetos que habían empezado a fumar esporádicamente notificaron algún síntoma de dependencia de la nicotina a las cuatro semanas de haber empezado a fumar una vez al mes. Uno o más síntomas fueron notificados por 60 de estos individuos (63\%), de los cuales $62 \%$ habían notificado el primer síntoma antes de empezar a fumar diariamente o habían empezado a fumar diariamente solamente después de haber tenido el primer síntoma. Estos resultados llevaron a los investigadores, de la Universidad de Massachusetts, a la conclusión de que los primeros síntomas de dependencia de la nicotina pueden aparecer a los pocos días o semanas de iniciado el consumo ocasional, a menudo incluso antes del consumo diario. Es primera vez que se obtienen datos de esta naturaleza. Para explicar el hecho de que algunas personas no se vuelven adictos a pesar de que fuman a diario, los investigadores postulan que podría haber tres tipos de fumadores: los que adquieren la adicción muy rápido, los que se tornan adictos gradualmente después de fumar con más regularidad, y los que pueden fumar poco o dejar el hábito y reiniciarlo sin volverse adictos. También existe la posibilidad de que los adolescentes sean más sensibles a la nicotina que los adultos. En todo caso, estos resultados ponen de manifiesto la necesidad de advertirles a los adolescentes que es muy difícil, si no imposible, jugar con el cigarrillo unos cuantos días y después dejarlo. La mayor parte de las veces ello conduce a una adicción que dura el resto de la vida. (DiFranza JR, Rigotti NA, McNeill AD, Ockene JK, Savageau JA, St Cyr D, et al.) Initial symptoms of nicotine dependence in adolescents. Tob Control 2000;9(3):313-319.)

\section{Uso del tampón para diagnosticar enfermedades de transmisión sexual}

Las infecciones genitales son causa importante de morbilidad en países en desarrollo y entre sus posibles consecuencias se encuentran la prematuridad y el bajo peso al nacer en hijos de mujeres afectadas. Lamentablemente, el diagnóstico de estas afecciones por la técnica tradicional, que exige un examen vaginal con un espéculo para obtener un hisopado de exudado cervical y vaginal, plantea dificultades en países de pocos recursos, donde no siempre se dispone de microscopios o del instrumental para el examen ginecológico en los consultorios de nivel primario. Un estudio reciente ha arrojado datos alentadores según los cuales se puede prescindir de un examen ginecológico invasor mediante el uso de tampones con exudado vaginal para el diagnóstico de enfermedades de transmisión sexual (ETS). En el estudio, que se efectuó en Sudáfrica en 1030 mujeres asintomáticas, se cultivaron hisopados vaginales obtenidos por el método tradicional y se sometieron a reacción en cadena de la polimerasa los exudados obtenidos de tampones que habían permanecido en la vagina durante una hora. En ambos casos las pruebas se orientaron hacia la detección de Trichomonas vaginalis.

Los tampones permitieron diagnosticar 247 casos de tricomoniasis, mientras que con el método tradicional solamente se detectaron 191 casos, lo cual indica que la sensibilidad de las pruebas fue mayor en el primer caso que en el segundo. En estudios dirigidos en años anteriores por el mismo investigador, la especificidad y sensibilidad de las pruebas efectuadas con tampones también se habían mostrado altas en el caso de la vaginosis bacteriana. 
La disponibilidad de un dispositivo que les permita a las propias pacientes recolectar especímenes en su casa para el diagnóstico de ETS posee enormes ventajas en distintos contextos. En países industrializados, elimina el estigma de tener que acudir a una clínica de ETS; en el mundo en desarrollo, facilita la realización de estudios poblacionales, necesarios para calcular la magnitud del problema de las infecciones asintomáticas o que pasan desapercibidas, las cuales contribuyen de manera importante a la transmisión del VIH. El tamizaje de la población también permite evaluar la necesidad y eficiencia de los programas para el control de las ETS. Los especímenes de orina, cuyo uso se ha propuesto para realizar este tamizaje, tienen limitaciones técnicas que llevan al subdiagnóstico de esas enfermedades. El aspecto más halagador de los datos obtenidos en este estudio africano es la posibilidad de usar tampones para diagnosticar infecciones en mujeres que no tienen flujo vaginal. (Gottlieb S. Tampons could be used to diagnose STDs. [News]. Br Med J 2000;321:978; Wilkinson D, Novela N, Kharsany A, Connolly C, Sturm AW. Tampon sampling for diagnosis of bacterial vaginosis: a potentially useful way to detect genital infections? J Clin Microbiol 1997;35(9):2408-2409.)

\section{Beneficios de la vitamina $C$ en fumadores con enfermedad coronaria}

El tabaquismo, factor de riesgo ampliamente conocido de enfermedad cardiovascular, afecta tanto a la circulación coronaria como a la periférica. Se especula que debido a su elevado contenido de oxidantes, el humo de tabaco produce lesiones oxidativas en el endotelio vascular. De hecho, se ha detectado disfunción endotelial en las arterias braquial y coronaria en fumadores de todo tipo, hasta en los que "fuman" por inhalación pasiva.

El ácido ascórbico o vitamina $C$ es el antioxidante hidrosoluble que se encuentra en mayores cantidades en el plasma de la sangre humana; protege a los lípidos contra daños perioxidativos porque destruye las moléculas de superóxido y de otras formas reactivas de oxígeno. En fumadores, las concentraciones plasmáticas y tisulares de vitamina $C$ son más bajas que en personas que no fuman. Hay datos que indican, además, que la vitamina $\mathrm{C}$ mejora la vasodilatación de origen endotelial en el antebrazo de personas fumadoras. En personas hipertensas, la vitamina $C$ ha mejorado la parte de la contractilidad de las arterias coronarias epicardíacas que depende del endotelio, lo cual indica que, al menos parcialmente, en estos casos la disfunción coronaria se atribuye a un estrés excesivo por oxidación.
Un grupo de investigadores, basándose en las observaciones anteriores, planteó la hipótesis de que los efectos del tabaquismo podrían extenderse más allá de las arterias epicardíacas a la microcirculación coronaria y afectar a la irrigación miocardíaca. Con el fin de poner a prueba esta hipótesis, midieron la reserva sanguínea del miocardio y de las coronarias mediante tomografía por emisión de positrones (positron emission tomography, $\mathrm{PET}$ ), antes y después de la administración de vitamina $C$, en 11 fumadores asintomáticos y 8 miembros de un grupo testigo integrado por personas que no fumaban. La reserva sanguínea de las coronarias, que es una medida integral del flujo sanguíneo por estas arterias, fue determinada tanto en las coronarias epicardíacas mayores como en la microcirculación de la zona. La reserva coronaria de los fumadores mostró una reducción de $21 \%$ en comparación con la de miembros del grupo testigo $(P<0,05)$, pero se normalizó después de la administración de vitamina C. En cambio, esta vitamina no tuvo efecto alguno en los individuos que no fumaban.

Este estudio es el primero en demostrar que los efectos prooxidativos del tabaquismo se extienden más allá de las arterias epicardíacas hasta la microcirculación coronaria y afectan a la regulación del flujo de sangre por el miocardio. La vitamina $C$ reestablece la capacidad reactiva de la microvasculatura coronaria y la reserva coronaria en fumadores, lo cual demuestra que el efecto nocivo del cigarrillo se debe, al menos en parte, a un aumento de los procesos de oxidación que generan estrés celular. (Kaufmann PA, Gnecchi-Ruscone T, di Terlizzi M, Schäfers KP, Lüscher TF, Camici PG. Coronary heart disease in smokers: vitamin $\mathrm{C}$ restores coronary microcirculatory function. Circulation 2000; 102:1233-1238.)

\section{Por qué hay resistencia a la cloroquina en algunos casos de malaria}

Según datos recién publicados, diversas mutaciones en uno solo de los genes de Plasmodium falciparum -el gen pfcrt del cromosoma 7, que corresponde a la proteína PfCRT de la membrana de la vacuola digestiva - son las responsables de la resistencia del parásito a la cloroquina. Se cree que las mutaciones genéticas se asocian con una acidificación del medio interno de la vacuola digestiva que podría alterar las concentraciones de cloroquina o reducir la fijación del fármaco a la hematina. El gen pfcrt ha sido identificado en cepas de parásitos de América del Sur, África y Asia. Anteriormente se pensaba que la resistencia a la cloroquina, al haber aparecido independientemente en cepas del Viejo y 
Nuevo Mundo, era atribuible a distintos genes, lo cual dificultaba la elaboración de marcadores genéticos para la detección de cepas de plasmodios resistentes en distintas partes del mundo. El estudio reciente ha revelado que todas las cepas africanas y asiáticas de $P$. falciparum resistentes a la cloroquina poseen una de dos variantes del gen $p f c r t$ que difiere del gen en cepas no resistentes por siete $u$ ocho mutaciones diminutas. En América del Sur, la resistencia a la cloroquina se asocia con otras variantes del gen $p f c r t$ con muchas mutaciones, lo cual respalda la teoría de que la resistencia surgió independientemente en el Nuevo Mundo. Lo importante, sin embargo, es que todas las variantes resistentes de las tres regiones poseen dos mutaciones específicas del gen $p f c r t$.

El hallazgo del gen $p f c r t$, tras más de 15 años de estudios, tiene dos implicaciones favorables: 1) ayudará a los investigadores a entender mejor las bases moleculares de la resistencia y, por lo tanto, a encontrar nuevos fármacos antimaláricos; y 2) permitirá que los científicos en zonas maláricas efectúen tamizajes para detectar la presencia de cepas de $P$. falciparum resistente a la cloroquina.

Aunque los científicos creen haber encontrado la clave de la resistencia a la cloroquina, fármaco antimalárico barato que ha sido ampliamente utilizado en poblaciones de escasos recursos, falta contestar varios interrogantes: ¿Qué función desempeña el gen $p f c r t$ en la resistencia a otros antimaláricos? ¿Por qué ciertas formas de cloroquina modificada muestran igual eficacia contra cepas de $P$. falciparum resistentes y sin resistencia? Esta última observación ha llevado a los investigadores a formular un segundo modelo hipotético, según el cual las mutaciones que alteran la proteína PfCRT pueden afectar, directa o indirectamente, al movimiento de la cloroquina a través de la membrana del compartimiento digestivo del parásito. Actualmente se efectúan abundantes estudios para dilucidar estos mecanismos. (Fidock DA, Nomura T, Talley AK, Cooper RA, Dzekunov SM, Ferdig MT, et al. Mutations in the P. falciparum digestive vacuole transmembrane protein PfCRT and evidence for their role in chloroquine resistance. Molec Cell 2000;6:861-871.)

\section{Vacuna contra el cólera protege a una población peruana}

En un estudio cuyos resultados se revelaron en mayo, se puso a prueba en el Perú una vacuna oral contra el cólera que redujo el número de episodios de diarrea en $61 \%$ después de tres dosis. La vacuna, cuya eficacia ya se había confirmado en Bangladesh con un régimen de administración distinto, se sometió a prueba en el Perú por recomendación de la OMS, puesto que en América Latina diversos factores que no existían en Bangladesh podrían reducir su eficacia: una mayor prevalencia de la cepa El Tor, una ausencia de inmunidad por falta de exposición y una alta prevalencia de sangre de tipo $\mathrm{O}$.

La vacuna se elabora a partir de células enteras de Vibrio cholerae inactivadas más un componente recombinante de la subunidad $B$ de la toxina del cólera. En este estudio con doble enmascaramiento, los investigadores usaron la vacuna contra el cólera producido por la cepa El Tor y administraron aleatoriamente a niños y adultos peruanos - un total de 17799 individuos de 2 a 65 años de edaddos dosis de vacuna o de placebo con dos semanas de intervalo, más una dosis de refuerzo 10 meses más tarde a 14997 de esos individuos.

Se llevó a cabo una vigilancia activa de casos de cólera que consistió en dos visitas semanales a cada domicilio. También se efectuó una vigilancia pasiva en uno de los hospitales de la localidad. Durante episodios de diarrea se cultivaron muestras de heces para detectar $V$. cholerae.

Después de las primeras dos dosis de vacuna (primer período de vigilancia), se aisló $V$. cholerae biotipo 01 de 17 de los vacunados y de 16 de los individuos que habían recibido placebo, con lo cual la vacuna mostraba una eficacia de $-4 \%$. Al cabo de tres dosis (segundo período de vigilancia), V. cholerae 01 se detectó en 13 vacunados y 32 de las personas que recibieron placebo. En este caso, la eficacia de la vacuna fue de 61\% (IC95\%: 28 a 79\%), lo cual representa una mejora considerable después de la dosis de refuerzo. La eficacia de la vacuna para la prevención de episodios de diarrea lo suficientemente graves para ingresar al paciente fue de $82 \%$ (IC95\%: 27 a 96\%) después de la dosis de refuerzo. En general, la vacuna se mostró más eficaz en personas mayores de 15 años.

Estos resultados indican que un régimen de tres dosis de la vacuna es el recomendable para países en desarrollo. Aún falta determinar si dos dosis confieren suficiente protección para viajeros y otras personas que carecen de inmunidad adquirida por la vía natural. (Taylor DN, Cárdenas $\mathrm{V}$, Sanchez JL, Bégué RE, Gilman R, Bautista C, et al. Two-year study of the protective efficacy of the oral whole cell plus recombinant B subunit cholera vaccine in Peru. J Infect Dis 2000;181:1667-1673.) 